\title{
Design of ship outfitting production management system based on Group Technology
}

\author{
Xiao Wang, Xiaoping Ma
}

\begin{abstract}
Based on the analysis of shipyard outfitting manufacturing process and production organization status, outfitting products are classified according to the similarity principle of group technology. The corresponding process coding system is established based on the processing procedure of outfitting products. Through business analysis of outfitting production process, extraction, decomposition and reorganization of outfitting design information, a set of outfitting production management system based on group technology is constructed.
\end{abstract}

Index Terms - Group technology; Ship outfitting; Process coding; Production management system.

\section{INTRODUCTION}

Outfitting is an important part of shipbuilding process, and the production and supply of outfitting parts is the premise to ensure the quality and efficiency of outfitting operation. There are many kinds of outfitting products, large quantity and low automation of manufacturing process, which lead to complex work station circulation and difficult on-site production management. It has become an inevitable trend to improve the level of outfitting production management by means of digitalization and informatization.

Group technology is a technology that can reasonably apply the similarity between objects, and it is one of the main basic technologies necessary for the establishment of modern shipbuilding mode [1]. Group technology is based on the process similarity of parts, so that products with different structural shapes but the same or similar processing positions can be planned and manufactured in groups. At present, the application of group technology in most ship enterprises focuses on regional outfitting, regional coating and the manufacturing and production process of pipe fitting family, but it is not fully used in the production and manufacturing of iron outfitting parts [2]. In this paper, by means of information technology, group technology is used to reasonably plan outfitting production, and effective solutions are proposed for the production management of outfitting.

\section{CURRENT SITUATION AND PROBLEMS}

Business process of outfitting workshop is shown in Figure 1.

Xiao Wang, School of Naval Architecture \& Ocean Engineering , Jiangsu University of Science and Technology, Zhenjiang, Jiangsu, China

XiaoPing Ma, Professor, School of Naval Architecture \& Ocean Engineering, Jiangsu University of Science and Technology, Zhenjiang, Jiangsu, China

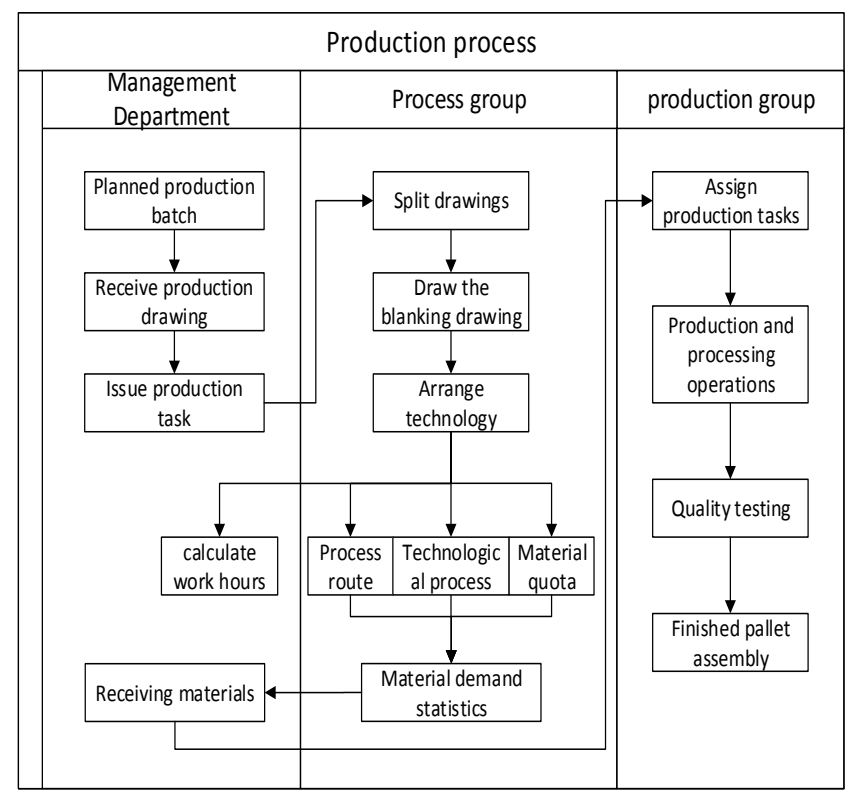

Fig.1 Workshop business flow chart

In the process of production and manufacturing, there are a lot of data transfer work done by human. The process team needs to carry out process planning work according to the design drawings and their own experience, including drawing splitting, drawing blanking drawings, preparing parts processing process tables, etc. The current production management process and process planning can basically meet the production demand, but the cost of human and material resources is not low. At the same time, there are some problems in the process of information flow, material supply, production and processing, and time statistics. It is shown in the following aspects.

\section{A. Disconnection between design and production}

The design department provides production design drawings and distributes them to the outfitting production workshop. The workshop process team needs to manually split a large number of drawings and extract and transcribe some process information in the drawings. In this process, the workload of workshop process group is huge and monotonous, which is easy to produce errors, and the generated process BOM data is not standard, which is not conducive to subsequent workshop picking and production.

\section{B. Material supply does not match production plan}

The formulation of the plan is lack of information-based means, which only relies on the flow of Excel forms, and cannot automatically associate with various plans such as the schedule plan, monthly plan, Bi weekly rolling plan, etc., which leads to the information lag of the material storage department and the situation that the material supply is not timely. 


\section{Chaotic production rhythm and low efficiency}

Due to the large number of outfitting products and different parts required between different products, there are many materials in the production process, and the field logistics is very complex. There are a lot of processing equipment needed for products. The diversification of processing objects and processing equipment leads to the complexity of production organization. In addition, rough workshop plan and random production arrangement lead to poor continuity of the whole production process and chaotic production rhythm.

\section{Cost accounting is not in place}

Due to the lack of classification standards for outfitting parts, lack of basis for standard production cycle, lack of standard quantity system and working hour quota, shipyard often uses experience estimation or weight as a unit to define in labor settlement. Such a way is limited to the subjective factors of the staff, and the accuracy is poor. Some outfitting parts with similar weight are difficult to make. For example, the actual working hours of the platform are significantly greater than that of the vertical ladder with the same weight. Therefore, it is necessary to establish a standard working hour quota to provide a reasonable basis for labor settlement and improve the enthusiasm of workers.

\section{CLASSIFICATION OF OUTFITTING PRODUCT TYPES}

The production and processing process of outfitting parts includes blanking, processing, assembly, welding, polishing, coating and other links, among which the processing includes hot bending, cold bending, punching, drilling and other ways, and the process is relatively complex.

In order to facilitate the management, shipyard usually takes pallets as the unit for production management in the production process of outfitting parts. Although this way can directly connect with the schedule in the plan management level, it reduces the management workload on the surface, but in fact, the standardized production process can not be formed in the production process, and the advantages of the same type and batch production are brought into play. At the same time, a large number of production hours are consumed, so it is difficult to provide data basis for the quota management of outfitting parts.

In view of the above problems, in order to make a variety of small batches of outfitting parts according to the production characteristics and give full play to the advantages of the same batch of outfitting parts, it is necessary to subdivide the types. On this basis, the production time of each type of outfitting parts is determined to achieve the purpose of fine management. The methods of product classification include inspection method, production process grouping method, feature coding classification method and fuzzy clustering method. Due to the rich variety and large weight difference of outfitting products, and the large similarity in the shape, specification and processing process of parts, the most appropriate classification method is to divide the parts by the similarity degree of parts process and the weight after assembly, and the division details are shown in Table 1.
Tab.1 Classification of outfitting product types

\begin{tabular}{|c|c|c|c|}
\hline $\begin{array}{l}\text { Serial } \\
\text { number }\end{array}$ & $\begin{array}{l}\text { Outfitting } \\
\text { category name }\end{array}$ & $\begin{array}{l}\text { Category } \\
\text { coding }\end{array}$ & $\begin{array}{l}\text { Characteristic } \\
\text { process }\end{array}$ \\
\hline 01 & Straight ladder & F.LV & Punching \\
\hline 02 & Heavy ladder & F.LH & $\begin{array}{l}\text { Punching, } \\
\text { pressing }\end{array}$ \\
\hline 03 & Railing & F.RL & Cold bending \\
\hline 04 & Mooring & F.ME & $\begin{array}{l}\text { Compression } \\
\text { type }\end{array}$ \\
\hline 05 & Flagpole & F.MT & $\begin{array}{l}\text { Fire bending, } \\
\text { drill hole }\end{array}$ \\
\hline 06 & $\begin{array}{l}\text { Equipment } \\
\text { base }\end{array}$ & F.SUP & drill hole \\
\hline 07 & Bin & F.TK & $\begin{array}{l}\text { Cold bending, } \\
\text { drilling, } \\
\text { metalworking }\end{array}$ \\
\hline 08 & Hatch cover & F.HC & \\
\hline 09 & Door & F.DR & Fire bending \\
\hline 10 & Platform & F.PF & \\
\hline 11 & Grille & F.MG & \\
\hline 12 & Winding stairs & F.WS & $\begin{array}{l}\text { Fire bending, } \\
\text { cold bending, } \\
\text { drilling }\end{array}$ \\
\hline 13 & Stepping & F.SP & Fire bending, \\
\hline 14 & $\begin{array}{l}\text { Type of raw } \\
\text { material }\end{array}$ & F.FB & \\
\hline 15 & Backing plate & F.BAP & \\
\hline 16 & Inclined ladder & F.LI & $\begin{array}{l}\text { Drilling, } \\
\text { flanging }\end{array}$ \\
\hline 17 & Eye plate & F.EP & Metalworking \\
\hline 18 & $\begin{array}{l}\text { Aluminum } \\
\text { platform }\end{array}$ & F.PF.A & $\begin{array}{l}\text { Drilling, } \\
\text { metalworking, } \\
\text { pressing, } \\
\text { flanging, } \\
\text { cutting }\end{array}$ \\
\hline 19 & Sidelights & F.ESL & $\begin{array}{l}\text { Cold bending, } \\
\text { drilling, } \\
\text { flanging }\end{array}$ \\
\hline 20 & Shelf & F.SE & \\
\hline
\end{tabular}

On the basis of the above classification, it is necessary to further subdivide the components of the products according to the process characteristics, and the degree of division depends on the specific processing capacity of the outfitting production workshop of the shipyard. A set of suitable manufacturing process coding rule system can be used as the basic work of process classification of parts and components, so as to facilitate the subsequent splitting and reorganization of outfitting BOM according to process attributes, and to plan production batches.

\section{MANUFACTURING PROCESS CODE RULE DEFINITION}

Coding rule is the basic work of group technology. In the field of shipbuilding, based on the research of engineering work breakdown, there has been a relatively mature system for outfitting pallet coding and material coding, but there is no suitable coding system at the level of manufacturing technology, which is difficult to meet the needs of outfitting Group production. 
During the production of outfitting parts, it is necessary to group them according to the structural types, materials, processing flow and surface treatment methods of products and parts. It is an important basic work to set up a set of manufacturing process coding rules applicable to their production. A good coding rule should have the following conditions: be able to cover the specific types of outfitting products; be able to describe the main structure and process feature information of its parts; be convenient for the expression and storage of part information; be able to code with appropriate length, clear meaning and certain expansibility. According to the manufacturing process characteristics of outfitting parts, the manufacturing process coding rules as shown in Figure 2 are designed.

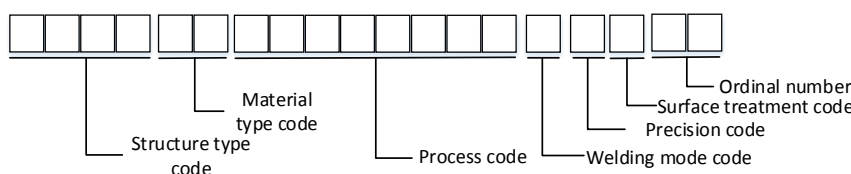

Fig.2 Rules for manufacturing process coding of outfitting parts

The meaning of each field code is as follows:

Structure type code: used to describe the specific type of parts and outfitting parts, and divide the parts according to the parts list of outfitting parts.

Material type code: it is used to distinguish the material types of parts. The usage is a joint code, in which 00-19 represents stainless steel, 20-39 represents carbon steel, 40-49 represents aluminum products, and 50-99 represents other types of materials.

Machining process code: used to describe the main machining process of the part after blanking. There are 9 typical processes preset in total. 0 or 1 indicates whether the part needs to go through a certain process.

Welding method code: used to describe the assembly and welding method of parts.

Precision Code: used to describe the precision requirements of parts processing.

Surface treatment code: used to indicate the surface treatment type of parts, such as primer, galvanizing, etc.

Serial number: used to indicate the serial number of outfitting products under the same manufacturing work.

\section{Design OF Outfitting Production Management SYSTEM}

In view of the problems existing in the outfitting production management process, according to the processing characteristics of outfitting products, building a set of outfitting production management system based on group technology can effectively improve the digitalization and automation of the production process [3].

\section{A. System architecture design}

The architecture mode of the system has a great influence on the function, performance and development strategy of the system. Based on the successful implementation experience of production management system in other industries and the actual situation of shipyard, the system follows the design principle and chooses a more mature C / S three-tier architecture based on. Net framework, which is divided into user interface layer, business logic layer and data access layer,
Data transfer between layers is completed by reading request. The system architecture is shown in Figure 3.

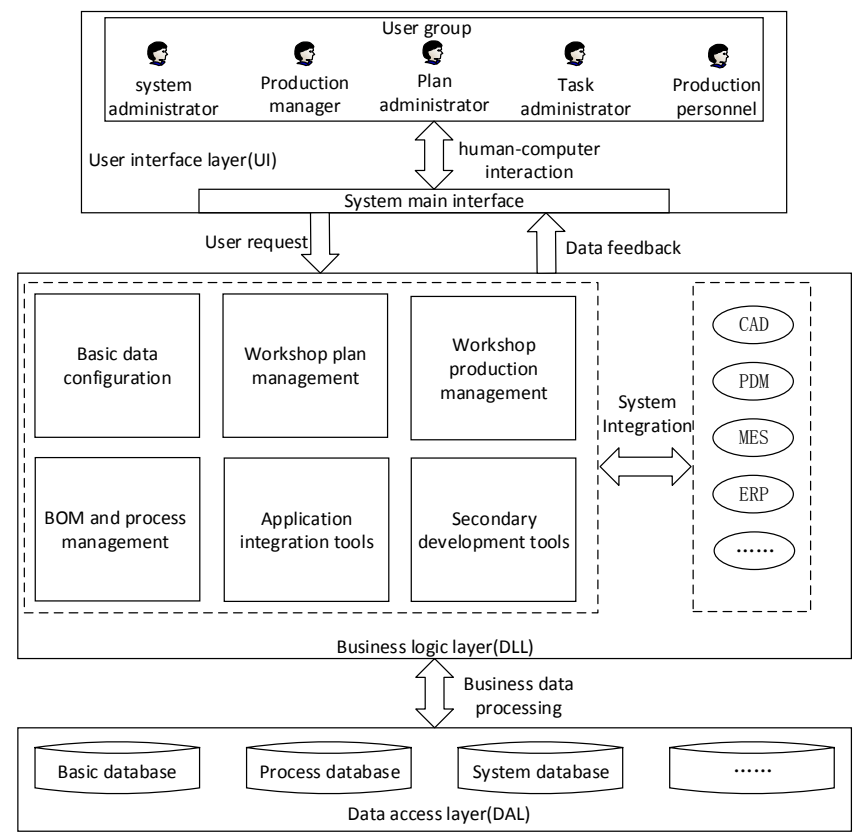

Fig.3 System architecture

\section{B. System operation process design}

The system is based on the original outfitting production management business process of the shipyard, with the BOM data of each stage of outfitting products as the core, so that the design model data in the system can be directly converted into process data to guide the field production according to certain rules and reasoning mechanism, and the work of the original workshop process group can be directly completed by the system. The overall operation flow of the system is shown in Figure 4.

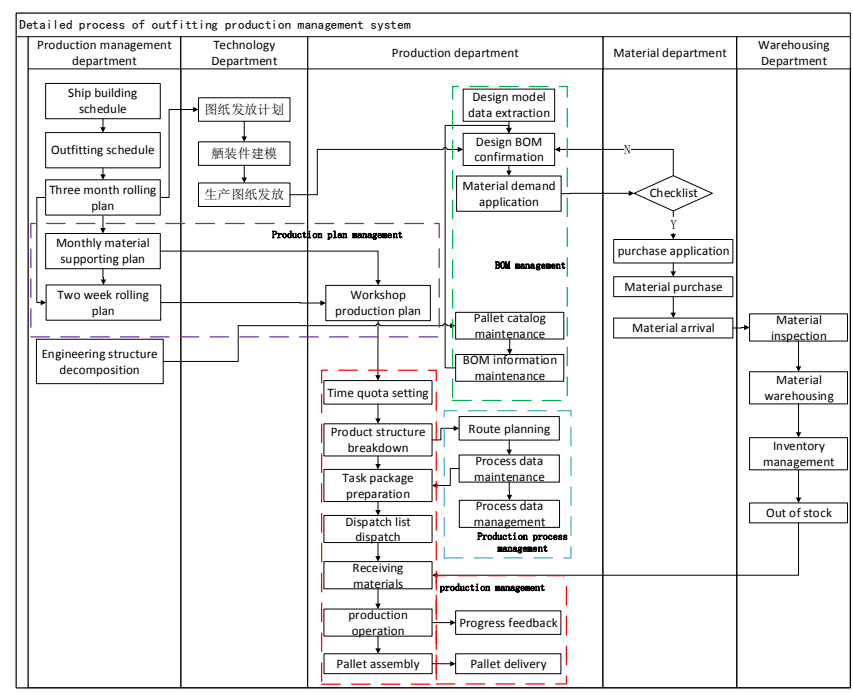

Fig.4 Operation process of outfitting production management system

\section{System function module design}

According to the role use case and system operation business process, the functional structure of outfitting production management system is designed as shown in Figure 5. 


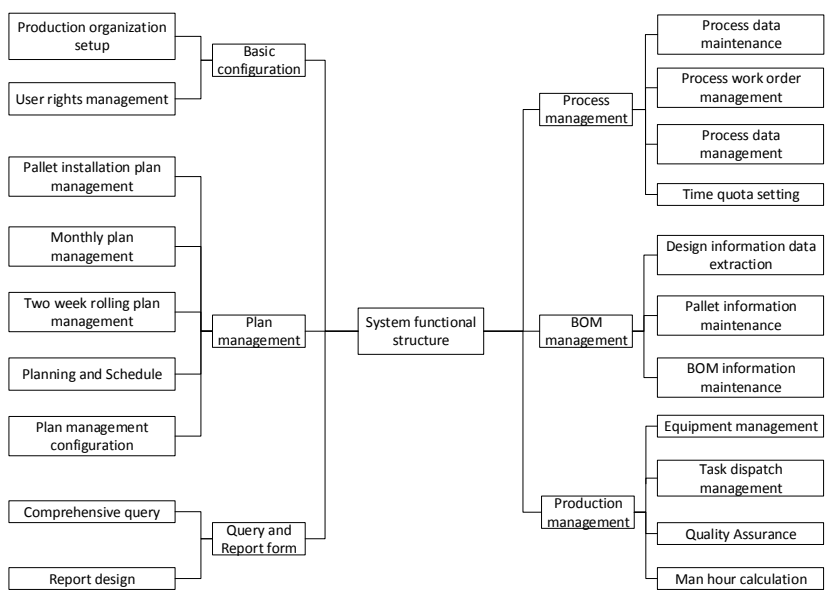

Fig.5 Function structure of outfitting production management system

According to the system operation process and functional structure, the main functional modules are introduced as follows:

1) Basic configuration

Set up the production organization and personnel according to the management structure, set up the authority for different roles such as workshop administrator, team leader and operation personnel in the production process, and realize the unified management of authority.

2) Plan management

According to the production schedule issued by the shipyard, prepare the pallet supporting plan, According to the production schedule, the personnel of each work station shall feedback the plan in the system, Administrator adjusts the production plan in real time according to the actual production situation and the feedback plan.

3) BOM management

Through the interface integration with 3D ship design software, the design model information data can be extracted directly Generate purchase BOM for material supply and process BOM for production, and maintain the information in the pallet catalog information under the project.

4) Process management

Analyze the extracted design model information data and define the specific outfitting process flow. Classify and summarize according to the process attribute of parts, and generate the material list corresponding to the station. Working hours quota of different outfitting products shall be established according to the type and weight.

5) Production management

According to the specific classification of outfitting products and parts, the production tasks shall be reasonably decomposed to form production batches according to types and processes. The application of group technology is realized by task dispatch through the split and combination of work order types.

6) Query and report

Summarize the production information according to the requirements, help the workshop management personnel to understand all kinds of information in the production process and the completion progress. Through the analysis of the data in the report, the managers can have a deeper understanding of the production situation in the workshop and make corresponding adjustment decisions.

\section{CONCLUSION}

This paper analyzes and summarizes the problems existing in the production management of outfitting parts in shipyard, The outfitting products are classified by group technology similarity principle; The coding rules of outfitting manufacturing process are established, which creates the basic conditions for the establishment of process database and the decomposition of production tasks; Based on business process, the function module and operation process of outfitting production management system based on group technology are designed, which provides reference for the integration of shipbuilding design, process, production and management.

\section{REFERENCES}

[1] Zhou Yangsheng. Research on the application of ship outfitting group technology and pallet management in ship building [D]. Harbin Engineering University, 2011

[2] Yuan Zhiying, Xue Zengfeng. Informatization of ship pipe production based on group technology [J]. Shipbuilding technology, 2010 (02): 44-46

[3] Wang Peng, Wang Ying. Design and implementation of coding system based on manufacturing characteristics [J]. Electronic design engineering, 2018,26 (13): 9-13

Xiao Wang, School of Naval Architecture \& Ocean Engineering, Jiangsu University of Science and Technology, Zhenjiang, Jiangsu, China

XiaoPing Ma, Professor, School of Naval Architecture \& Ocean Engineering, Jiangsu University of Science and Technology, Zhenjiang, Jiangsu, China 